\title{
James Parkinson's Essay on the Shaking Palsy
}

\begin{abstract}
SHAKING PALSY. (Paralysis agitans) Involuntary tremulous motion, with lessened muscular power, in parts not in action and even when supported; with a propensity to bend the trunk forward and to pass from a walking to a running pace: the senses and intellects being uninjured.
\end{abstract}

So begins James Parkinson's Essay on the Shaking Palsy.' Parkinson, a London surgeon, published his Essay in 1817 but it seems to have attracted little attention at the time. About six decades passed before the great French neurologist Jean-Martin Charcot spoke of the maladie de Parkinson as a name for the disorder characterised by tremor at rest, rigidity, characteristic facial immobility and particular disturbances of gait and posture. After that, though the illness was well-enough recognised, neither it nor Parkinson's Essay attracted more than passing interest in medical writings. This was probably because, as Rose ${ }^{2}$ wrote in 1903: 'This disease is generally put down in most textbooks as one that the physician can do little for by way of relief or cure.' Rose hoped to offer some solace saying: 'I wish in this communication to show that the symptoms can be much relieved and life prolonged by alleviation of the same.' He had found that, as had been suggested some months earlier by Williamson and Bury, hyoscine hydrobromide relieved his patient's tremor and after 15 months' treatment with it she felt much better in every way. Sporadic papers appeared over the following years in which other anticholinergic drugs were reported to have useful effects. But it was not until the appearance of encephalitis lethargica was followed by the development of a post-encephalitic syndrome in many patients that attention turned to comparing this syndrome with Paralysis agitans. Only then, it seems, was Parkinson's Essay re-considered - see Cruchet 1925. ${ }^{3}$ But by then his little tract had become very rare and despite reprinting it remained that way so that, in 1955 on the bicentenary of Parkinson's birth, Macdonald Critchley was to write: ${ }^{4}$

JAMES PARKINSON'S little monograph, originally published in London in 1817, has become so rare as to constitute nowadays a valuable item in a medical library. About thirty years ago a facsimile edition was produced and distributed by the American Medical Association Press. Even these latter volumes have now become scarce. The bicentenary of James Parkinson's birth in 1755 therefore offers an opportunity for yet another reissue of the original essay.
To this bicentenary volume, Sir Francis Walshe contributed an excellent functional analysis, still well worth reading, of the features that Parkinson described in his Essay seen from the standpoint of the mid-20th century and studied by modern methods.

\section{The Sibbald Library copy}

The Sibbald Library is fortunate to have a copy of the original Essay; it is inscribed on the title page 'To the Editor of the Quarterly Edinb. Med[ical] and Chirurg[ical] Journal A'Who the donor, $A$, was and when and how the copy passed from the Editor to the Library is unknown. The book is not listed in the Library Catalogue of 1863 but appears in that of 1898. The puzzle is compounded because there does not seem to have been a Quarterly or an Edinburgh Medical and Chirurgical Journal though there was certainly a Medico-Chirurgical Society of Edinburgh; in fact there were two societies of this name, the first founded in 1767, the second in $1821 . .^{5}$ In its second incarnation, still apparently extant, the Society published Transactions from 1824. Perhaps it was to an editor of these Transactions that the volume was presented.

\section{Parkinson's Essay}

What then of the Essay itself? Just what did Parkinson describe and why did he consider that his observations would be useful to medical practitioners? Parkinson is often loosely credited with being the first to describe the disease that now bears his name. In fact, he described as a single condition a syndrome with a number of characteristic features that he named 'The Shaking Palsy' for which he also provided the Latin name Paralysis agitans - simply a translation of the English. All of the individual features of this syndrome had been described separately by others in the past. He was very conscious of the incompleteness of his treatise as he explained in his Preface: '...some conciliatory explanation should be offered for the present publication; in which it is acknowledged, that mere conjecture takes the place of experiment; and that analogy is the substitute for anatomical examination, the only sure foundation for pathological knowledge.' Also, he continued, '... it has not yet obtained a place in the classification of nosologists: some have regarded its characteristic symptoms as distinct and different diseases, and others have given its name to diseases differing essentially from it.' $\mathrm{He}$ is absolutely clear that he is not the first to describe any of the various individual symptoms; some of which have 
descriptions going back to Galen.What is new is his claim that the co-occurrence of these symptoms indicates the presence of a distinct disease which he has recognised in a small number of patients, a disease which is progressive though its origin is unclear, whose pathology is unknown and for which there is no established treatment. It has been proposed that his reason for writing the Essay was that, as he pointed out, the disease was absent from the classifications of the nosologists - presumably the implication of this explanation is that his principal aim was to make a place for it in such schemes. I do not think there is any evidence that Parkinson had any such intention nor even that he set any store by its inclusion in nosologies or otherwise.

\section{Nosologies}

Theoretical aspects of medicine in the later 18th century were dominated by attempts to classify disease. The ageold problem of trying to understand the relationship of one disease to another had never attracted a satisfactory solution. Following Sydenham, it had been realised that diseases and symptoms were not always the same thing and that, at least in principle, similar symptoms might occur in association with clearly different diseases. But old habits die hard and, in practice, the distinction between symptom and disease was often blurred - when it was made at all. The most obvious example is that of fever which continued to be regarded as a disease - or, more correctly, a whole family of diseases - well into the 19th century even though it was also recognised that it could be, on occasion, a symptom accompanying some other condition. During the 18th century the classification of plants into genera, classes and species - most notably by Linnaeus - seemed to offer a model for a classification of disease. Significantly, Linnaeus was a medical doctor as well as a botanist. The pairing of botany with medicine had a long history dating back to before the 16th century during which Matthioli, Fuchs and Lonicer were distinguished practitioners in both fields. This early association was a natural one since plants formed such a large part of the therapeutic armamentarium. It is therefore unsurprising that from the 1760s a French physician-botanist in Montpellier, Boissier de Sauvages, began to try to classify diseases in the way in which Linnaeus had classified plants. Linneaus himself became involved later and, by the end of the 18th century, several such schemes of nosology had been developed. Upon his appointment to the Chair of Medicine in Edinburgh, the Scots physician William Cullen undertook to publish the existing nosologies and, for the benefit of his students, to add to them a classification of his own. Not surprisingly, since what were being classified were essentially symptoms and signs, on the basis of no more than apparent resemblances between them, the whole enterprise added very little indeed to the understanding of disease or the advance of medicine. For a brief but informative account of the attempts of the nosologists, see Kendall. ${ }^{6}$ It is very easy to see that the quite artificially separated groups of signs and symptoms were likely to be confused with disease entities. In the general absence of much understanding of pathology or pathophysiology, and at a time when the study of normal physiology was in its infancy, the nosologies had the effect of obscuring relations between groups of signs and symptoms which did have their origin in common pathology and losing them in the morass of lists of symptoms which were thought to resemble each other. Parkinson's achievement was that he recognised that a collection of signs and symptoms, which had previously been classified by the nosologists as separate entities, in fact represented a single disease. In his Essay he was not concerned with attacking the principles of the nosologists - indeed, he commends and defends Cullen's decision not to include 'tremor' as a disease and praises his shrewdness in claiming that tremor is always a symptom.

\section{Parkinson's description}

Parkinson elaborates the succinct paragraph which begins his work by considering each of the signs and symptoms in turn, reporting the earlier descriptions of them then showing by reference to a few cases how they combine to characterise the shaking palsy. However, two features which are regularly and characteristically found in Paralysis agitans are not mentioned by Parkinson; the characteristic immobile face devoid of expression and the presence of muscular rigidity. Why he did not notice (or record if he did notice) the lack of facial expression has puzzled commentators, one of whom even suggested that perhaps it was not present in the disease at the beginning of the 19th century; this seems highly improbable. As to rigidity, nowhere in his account does Parkinson describe carrying out physical examination of his patients as well as observing them. It may well be that a practitioner of his time, though he would be accustomed to feeling and counting the pulse and looking for fever by touching the skin, would have had no reason to test what we now call muscle-tone by passive manipulation of the limbs and so would not have detected muscular rigidity.

Parkinson was well aware of the miserable condition of patients with the established disease and explicitly sought means of offering them some relief. But this immediately raised the problem of finding some seat of the disease that might be susceptible to manipulation. He deduced from the areas affected that the cause of the disease must lie in the spinal medulla and perhaps in the brainstem. But he was acutely conscious of the complete lack of any anatomical evidence in his patients. He was, therefore, forced to argue by analogy from a report of a case in a French gentleman, which he thought to have been similar to Paralysis agitans, in which post-mortem examination showed evidence of damage to the cervical cord. For the modern reader it is stretching credulity very far to see much resemblance between the symptoms described in the French patient who, following an injury to his neck in 
a coach accident, developed progressive weakness of both arms and speech impairment over several years, and Parkinson's descriptions of patients with Paralysis agitans. Struggling to find an immediate (proximate) cause for the shaking palsy, Parkinson turns to a couple of cases of 'rheumatic' affection (as he says) of the upper limbs. These involved pain, paraesthesiae and weakness of one or both arms, coming on fairly suddenly, improving, but not completely resolving. Though he admits he is uncertain, Parkinson wonders if, perhaps, these represent the beginnings of what will become the shaking palsy. As a result of these observations, Parkinson proposes treatment by bleeding from the upper part of the neck, applying blisters there and 'a purulent discharge [should be maintained] by appropriate use of the Sabine Liniment'. This liniment was a highly irritating shrub oil, Oil of Savin, which contained podophyllotoxin. These traditional local measures directed to what he supposed to be the site of the pathology, the cervical cord and medulla, were all that Parkinson could offer, and he was painfully aware of their inadequacy.

But the Essay does not end there. Though he does not claim he has been able to do much to relieve the suffering of the patients whose disease he had defined, he hoped that, by calling attention to the existence of the shaking palsy as a distinct disease, he would encourage others to attempt to uncover its causes by 'anatomical examination' - unpleasant as he says such a process is. He invokes the names of John Hunter, Morgagni and Bailllie as pioneers in such 'anatomical' investigation and hopes that someone similarly talented will undertake this task. Hunter's name is particularly significant. Parkinson had attended a series of Hunter's lectures in 1785, taken them down in shorthand and later transcribed them. They were published by his son in $1833^{7}$ who hoped that these notes may '... supply the loss which surgical science has sustained by the destruction (by accident it is to be hoped) of the original notes from which Mr Hunter lectured.' In the Preface the younger Parkinson says: '...the lectures were attended by his Father (who was at that time in practice), with the view of selecting those pathological doctrines which were exclusively Mr Hunter's, and of conveying them as precisely as possible in his own words...'. Clearly, then, Parkinson was particularly interested in the pathophysiology of disease, a study which Hunter pioneered, and he recognised that methods of investigation like those of Hunter were the only means by which the pathology of Paralysis agitans might be discovered. Indeed, he is quite specific about his hopes: 'The disease had escaped particular notice; and the task of ascertaining its nature and cause by anatomical investigation, did not seem likely to be taken up by those who, from their abilities and opportunities, were most likely to accomplish it. That these friends to humanity and medical science, who have already unveiled to us many of the morbid processes by which health and life is abridged, might be excited to extend their researches to this malady, was much desired; and it was hoped, that this might be procured by the publication of these remarks.'

Here, then, we have the principal reason for the publication of Parkinson's Essay; to encourage investigation by postmortem examination of the cause of this disease whose existence as a distinct entity he had uncovered. It is difficult not to feel that Parkinson would have been disappointed by the many decades which passed before such investigations uncovered the changes in the basal ganglia that accompany his disease. Even now, for all that some aspects of its molecular pathology are at least partially understood, and some patients obtain dramatic relief from surgery or chronic brain stimulation, for many patients treatment is often very unsatisfactory and general means of relieving 'a tedious and most distressing malady' are, sadly, not yet with us. Parkinson's Essay deserves to be read today as an account of the struggle of a most humane practitioner to excite interest in a 'new' disease specifically in the hope of encouraging the study of its pathology and so, perhaps, in time providing means for its relief.

IML Donaldson

Honorary Librarian, RCPE (email i.m.l.d@ed.ac.uk)

\section{REFERENCES}

I Parkinson J. An Essay on the Shaking Palsy. London: Whittingham and Rowland for Sherwood, Neely, and Jones; 1817.

2 Rose A. Hyoscine As A Specific In Paralysis Agitans. Br Med J 1903; 2: 1589-90. http://www.jstor.org/stable/20278797

3 Paralysis Agitans And Post-Encephalitic Conditions. Professor Cruchet's Lecture. $\mathrm{Br}$ Med J 1925; I: 474-5. http://dx.doi. org/I0.1 I36/bmj.I.3349.474

4 Critchley, M. editor. James Parkinson (I 755-1824): A bicentenary volume of papers dealing with Parkinson's disease, incorporating the original Essay on the shaking palsy with the collaboration of William $\mathrm{H}$. McMenemy, Francis M. R. Walshe, J. Godwin Greenfield. London: Macmillan 1955.

5 Batty Shaw A.The oldest medical societies in Great Britain. Med Hist 1968; I2: 232-44. http://dx.doi.org/I0.1017/S00257273000I3272

6 Kendell RF. William Cullen's Synopsis Nosologiae Methodicae. In: Doig A, Ferguson JPS, Milne IA et al., editors. William Cullen and the Eighteenth Century Medical World. Edinburgh: Edinburgh University Press; 1993. p. 216-33.

7 Parkinson JWK. Hunterian reminiscences; being the substance of a course of lectures on the principles and practice of surgery, delivered by John Hunter, in the year 1785/taken in short-hand, and afterwards fairly transcribed by James Parkinson. Edited by his son, J.W.K. Parkinson, by whom are appended illustrative notes. London: Sherwood, Gilbert, and Piper; 1833. 